\title{
Phonological and orthographic coding in deaf skilled readers
}

Noemi Fariña $^{1}$, Jon Andoni Duñabeitia ${ }^{1}$ and Manuel Carreiras ${ }^{1,2,3}$

${ }^{1}$ BCBL. Basque Center on Cognition, Brain and Language; Donostia, Spain

${ }^{2}$ Ikerbasque, Basque Foundation for Science; Bilbao, Spain

${ }^{3}$ University of the Basque Country EHU/UPV, Bilbao, Spain

\section{Contact details:}

Noemi Fariña

Basque Center on Cognition, Brain and Language

Paseo Mikeletegi, 69, $2^{\text {nd }}$ floor

20009 - Donostia, Spain

n.farina@bcbl.eu 


\begin{abstract}
Written language is very important in daily life. However, most deaf people do not achieve good reading levels compared to their hearing peers. Previous research has mainly focused on their difficulties when reading in a language with an opaque orthography such as English. In the present study, we investigated visual word recognition of deaf adult skilled readers while reading in Spanish, a language with a transparent orthography, for which obligatory phonological mediation has been claimed. Experiment 1 showed a pseudohomophone inhibitory effect in hearing but not in deaf people. Experiment 2 showed similar orthographic sensitivity, as measured by the transposed-letter effect, for both groups. These results suggest that deaf skilled readers do not rely on phonological mediation, while maintaining the same level of orthographic sensitivity as hearing readers, thus suggesting that the use of phonological coding is not required to access the lexicon and meaning in a language with a transparent orthography.
\end{abstract}

Keywords: reading, lexical decision, deaf skilled readers, phonological coding, orthographic coding 


\section{Introduction}

Written language is an important channel for daily communication and for cultural transmission. Learning to read changes our brain (Carreiras et al., 2009), influences our cognitive machinery, including spoken language processing (Frost, Repp, \& Katz, 1988; Frost \& Katz, 1989; Ziegler \& Ferrand, 1998), and opens a new world of opportunities. However, most deaf people never achieve a good reading level and lag behind their hearing peers (Conrad, 1979; Taxler, 2000). Various authors have suggested that reduced access to speech phonology is the main underlying cause of their reading difficulties and the high percentage of deaf people who make a great effort to learn to read (Hanson \& Fowler, 1987; Perfetti \& Sandak, 2000). Even so, it is unclear whether, for example, explicit training of phonological awareness helps deaf individuals to achieve high reading proficiency (Campbell \& Wright, 1988; Izzo, 2002; Nielsen \& Luetke-Stahlman, 2002). Regardless of the difficulties in the development and acquisition of reading for deaf individuals and the role of phonology in this process, there are deaf adults who have achieved a high level of reading, equivalent to hearing peers. While most previous research has focused on the difficulties of deaf readers in relation to phonological processing (Colin, Magnan, Ecalle, \& Leybaert, 2007; Kelly \& Barac-Cikoja, 2007), in the present study we adopt a different perspective by focusing on deaf highly skilled readers and investigating their use of phonological and orthographic codes during reading in comparison to hearing readers.

Many studies have highlighted the importance of phonological coding and awareness for reading skills in deaf individuals (Hanson \& Fowler, 1987; Perfetti \& Sandak, 2000). The majority of studies that investigate the role of phonology in the deaf population do so through meta-phonological tasks and phonological awareness, which require explicit phonological judgments (Aparicio, Gounot, Demont, \& Metz-Lutz, 2007; Campbell \& Wright, 1988; Dyer, 
MacSweeney, Szczerbinski, Green, \& Campbell, 2003; Transler, Leybaert, \& Gombert, 1999; Waters \& Doehring, 1990). In addition, many of these studies focus on deaf children, where reading is still in the development phase. Our interest, on the other hand, is in studies that investigate the role of phonology in more implicit reading tasks, such as lexical decision between words and nonwords, and reading with deaf adult readers. Studies that use this paradigm, such as Transler and Reitsma (2005), show evidence for phonological coding in visual word recognition in deaf Dutch readers, but in this case the population studied was children. In contrast, the few other studies with deaf adults have reported no evidence for the use of phonological coding by deaf readers during word reading. For example, Bélanger, Baum and Mayberry (2012) concluded that skilled deaf readers might activate visual, orthographic and semantic codes during reading, but not phonological codes in French. Furthermore, Bélanger, Mayberry and Rayner (2013) investigated the phonological and orthographic preview benefit in parafovea in English readers. The authors manipulated whether, when reading sentences, the word processed in the parafovea corresponded to a homophone or an orthographically similar word to the target word, which only appeared once the eye gaze came to that word and it was within the foveal area. They showed that skilled hearing readers, skilled deaf readers and less-skilled deaf readers benefited from orthographic coding in parafoveal vision during reading, showing shorter fixations for target words in the orthographically similar condition. In contrast, only the hearing group benefited from phonological coding, since they showed shorter first fixations on the target word, suggesting that homophones seen in the parafovea were recognized and that phonological information influenced the subsequent reading time. This benefit and processing of phonological information during parafoveal viewing was not present in the deaf group. Mayberry, Del Giudice and Lieberman (2011) conducted a meta-analysis of 57 studies of reading outcomes in deaf 
adults and children. They showed that language ability (measured in terms of sign or spoken language comprehension and vocabulary production) accounted for $35 \%$ of the variance in reading ability, whilst speech phonological awareness accounted for $11 \%$ of the variance, a figure similar to that reported in hearing children (Mayer, 2007). Thus, although important, activation of phonological code may not be a determining factor for reading skills, at least in languages with opaque orthographies.

Importantly, previous studies have demonstrated that the presence of phonological mediation in tasks of word-processing is a necessary step to lexical access (Coltheart, Rastle, Perry, Langdon, \& Ziegler, 2001; Frost, 1998; Van Orden, Johnston, \& Hale, 1988). These studies conclude that the basis of word visual recognition rests on the phonological representation, rather than on the orthographic representation. However, this seems to depend on the degree of transparency of the language in which reading occurs (e.g., languages with a transparent orthography such as Spanish vs. languages with an opaque orthography such as English; Ehri, 1986; Frith, 1985; Harm \& Seidenberg, 2004; Share, 1995). Frost and Katz (1992) hypothesized that transparent orthographies are more easily able to support a word recognition process that involves phonological coding. In contrast, in opaque orthographies, readers can process printed words by relying on alternative strategies (e.g., by relying on the visualorthographic structure). Crucially, it has been shown that phonological codes are automatically accessed during reading in Spanish, a language with a transparent orthography (e.g., Carreiras, Perea, Vergara, \& Pollatsek, 2009; Pollatsek, Perea, \& Carreiras, 2005), suggesting that efficient phonological processing may be an obligatory step for word identification in transparent languages. 
Reading mechanisms in deaf skilled readers may be modulated by the nature of the orthographical system they have to master. Most research with deaf readers has been conducted in languages with an opaque orthography. Therefore, it is critical to investigate how deaf skilled readers carry out visual word recognition in a transparent orthography to better understand the real contribution of phonological processes to reading in this population. The current study focuses on deaf skilled readers of Spanish, a transparent language in which phonological coding has been claimed to be an obligatory and automatic step in the visual word recognition process. Besides, and in contrast to preceding studies relying on meta-phonological tasks, here we used a simple lexical decision task to test phonological and orthographic coding in skilled deaf readers. If phonological processes are at work in deaf skilled readers, the prediction is that they should certainly be seen during reading in a transparent orthography.

Hence, in the present study we investigated the role of phonological and orthographic processing in deaf and hearing skilled readers in Spanish, a language with a transparent orthography. Experiment 1 tested phonological processing in a lexical decision task with two types of nonwords: pseudohomophones (nonwords that sound like real words) and control nonwords. The pseudohomophone effect is one of the strongest indicators of phonological processing in visual word recognition (Briesemeister et al., 2009; Ferrand \& Grainger, 1994; Ziegler, Jacobs, \& Klüppel, 2001), as indicated by slower reaction times and/or more errors for pseudohomophones than control nonwords. Experiment 2 tested orthographic processing in a lexical decision task with two types of nonwords: transposed-letter nonwords (TL) and replacedletter nonwords (RL). The transposed-letter effect is a robust indicator of orthographic processing (Perea \& Lupker, 2004; Perea \& Carreiras, 2006), as shown by slower reaction times and more errors for TL nonwords than RL nonwords. 
On the one hand, if deaf skilled readers activate phonological codes they should perform like hearing readers and show longer reaction times and/or higher error rates for pseudohomophones than control nonwords. In contrast, if they do not activate phonological codes they should show no differences between pseudohomophones and control nonwords. On the other hand, if, similarly to hearing readers, deaf readers activate orthographic codes, then both deaf and hearing readers should show longer reaction times and/or higher error rates for transposed-letter nonwords than replaced-letter nonwords. Thus, the combination of the two experiments will show whether deaf skilled readers activate phonological and/or orthographic codes to the same extent as hearing readers, and to what extent phonological mediation is necessary for skilled reading in a language with a transparent orthography.

\section{Experiment 1: Phonological coding}

2.1. Method

\subsubsection{Participants}

Fifteen adult Spanish severely $(70-90 \mathrm{~dB})$ to profoundly $(>90 \mathrm{~dB})$ deaf proficient readers (11 females; mean age $=33.93$ years; $\mathrm{SD}=7.44$; range $=23-45$ ) participated in the study. All participants provided self-reports on their hearing loss, and reported having lost audition before the age of 3 (i.e., prelingual deafness). Also, all of them learned Spanish Sign Language before 10 years old and used it as main language for communication. In addition, most of them learned to read at an early age, particularly at school, except two who learned after 16 years old. Fifteen hearing Spanish readers ( 7 females; mean age $=29.13$ years; $S D=5.8$; range $=20-42$ years old $)$ were also included as a control group. All participants completed the ECL-2 reading assessment 
Test (De la Cruz, 1999) to assess their reading comprehension level. This test is a standardized reading test, which evaluates different types of texts and aspects of reading comprehension: knowledge of the meaning of words, synonyms, antonyms, understanding the meaning of sentences and the ability to integrate information into a text. The test consisted of five short paragraphs followed by multiple-choice questions, 27 in total. It is normed with a sample of 16year-olds and does not require a reading aloud task for percentile rating (which would have been problematic for the deaf group). Only participants who scored at least at the $75^{\text {th }}$ centile (more than 17 correct answers) on the test were included in the study and considered relatively skilled readers, and the two groups were matched according to the raw scores (deaf: mean=21.90, $\mathrm{SD}=3.08$, range $=18-27$; hearing: mean $=23.70, \mathrm{SD}=3.25$, range $=17-27$ ). All the participants also completed the Spanish version of LexTALE (Izura, Cuetos, \& Brysbaert, 2014), a lexical decision test comprising 60 real words and 30 nonwords that provides a good estimate of language knowledge (e.g., de Bruin, Carreiras, \& Duñabeitia, 2017; Lemhöfer \& Broersma, 2012). The final scores (in percentages) showed that both groups completed the test accurately, demonstrating a high language knowledge and no differences among the groups (deaf: mean $=91.16, \mathrm{SD}=13.22$; hearing: mean=95.66, $\mathrm{SD}=3.43 ; \mathrm{p}=.22$ ). The Raven Progressive Matrices test (Raven, Raven, \& Court, 1998) was also administered to all participants as a nonverbal intelligence test, which measures general cognitive ability and involves identifying the item that is missing from a series of figures. The basic version of the test, the Standard Progressive Matrices (SPM), consists of five series of 12 items, each of increasing complexity, requiring progressively greater cognitive capacity to encode and analyze information. This test is standardized by age and percentile scores can be obtained for different age groups, in this case, for adult population. We excluded participants with notably low percentiles (percentile $\leq 25$ ). 
The two groups were matched according to the scores (deaf: mean=84.87, $\mathrm{SD}=9.97$; hearing: mean=86.87, $\mathrm{SD}=10.32 ; \mathrm{p}>.250$ ). A total of 4 deaf and their corresponding 4 hearing control participants were excluded from the study because their scores in some of the tests were very low.

\subsubsection{Materials}

For word trials, 80 Spanish words between four and six letters long were selected (mean $\log$ word frequency in the EsPal database (Duchon, Perea, Sebastián-Gallés, Martí, \& Carreiras, 2013): 3.57, range: 3.01-3.87; mean number of letters: 5). For nonword trials, 80 Spanish base words between four and six letters long with a similar frequency to the first set were also selected (mean log word frequency: 3.96, range: $2.61-4.65$; mean number of letters: 5.29 ). These words were used to create (1) a pseudohomophone, by replacing one letter by another letter that corresponded to the same phoneme (e.g., the pseudohomophone javón created from the base word jabón, 'soap'), and (2) a control nonword in which one letter was replaced by another letter that corresponded to a different sound (e.g., the nonword jacón created from the same base word). Two lists were constructed such that each base word used to generate the nonwords appeared once in each list, either as a pseudohomophone or as a control nonword. Participants were randomly assigned to the two lists. In total, each participant completed 160 trials, 80 words and 80 nonwords ( 40 pseudohomophones and 40 control nonwords).

\subsubsection{Procedure}

The experiment was run individually in a room with no acoustic or visual distractions. Presentation ${ }^{\circledR}$ software (Version 0.70, www.neurobs.com) was used for stimulus presentation and recording of response times and accuracy. Each trial began with the presentation of a 
centered fixation cross $(+)$ for $500 \mathrm{~ms}$ followed by presentation of the stimulus word in lowercase font (25-pt. Courier New) for 1500 ms. Participants were instructed to press one of two buttons on the keyboard to indicate whether the letter string was a word ('M') or nonword ('Z'). Participants were instructed to respond as quickly and accurately as possible. The order of presentation of the stimuli was randomized for each participant and two response buttons were counterbalanced for word and nonword responses. Each participant completed eight practice trials prior to starting the experiment. The entire session lasted approximately eight minutes.

\subsubsection{Results}

Mean error percentages and response latencies for deaf and hearing readers are presented in Figure 1. Trials with incorrect responses $5.03 \%$ and $9.67 \%$ of the trials for deaf and hearing respectively) were excluded from RT analysis. First, RTs associated with responses shorter than $200 \mathrm{~ms}$ were discarded given that they were likely to correspond to involuntary button presses $(0.31 \%$ and $0.75 \%$ of the data of deaf and hearing group, respectively). Next, RTs above or below 2.5 standard deviations from the mean for each condition per participant were also excluded from the analysis of the response latencies $(1.89 \%$ of the data of the deaf group and $1.95 \%$ of the data of the hearing group). For word trials, t-tests were conducted on the error percentages and response latencies for hearing and deaf readers. For nonword trials, participant and item based ANOVAs were conducted on error percentages and response latencies following a 2 (Group: hearing, deaf) x 2 (Type of nonword: pseudohomophone, control) design. 

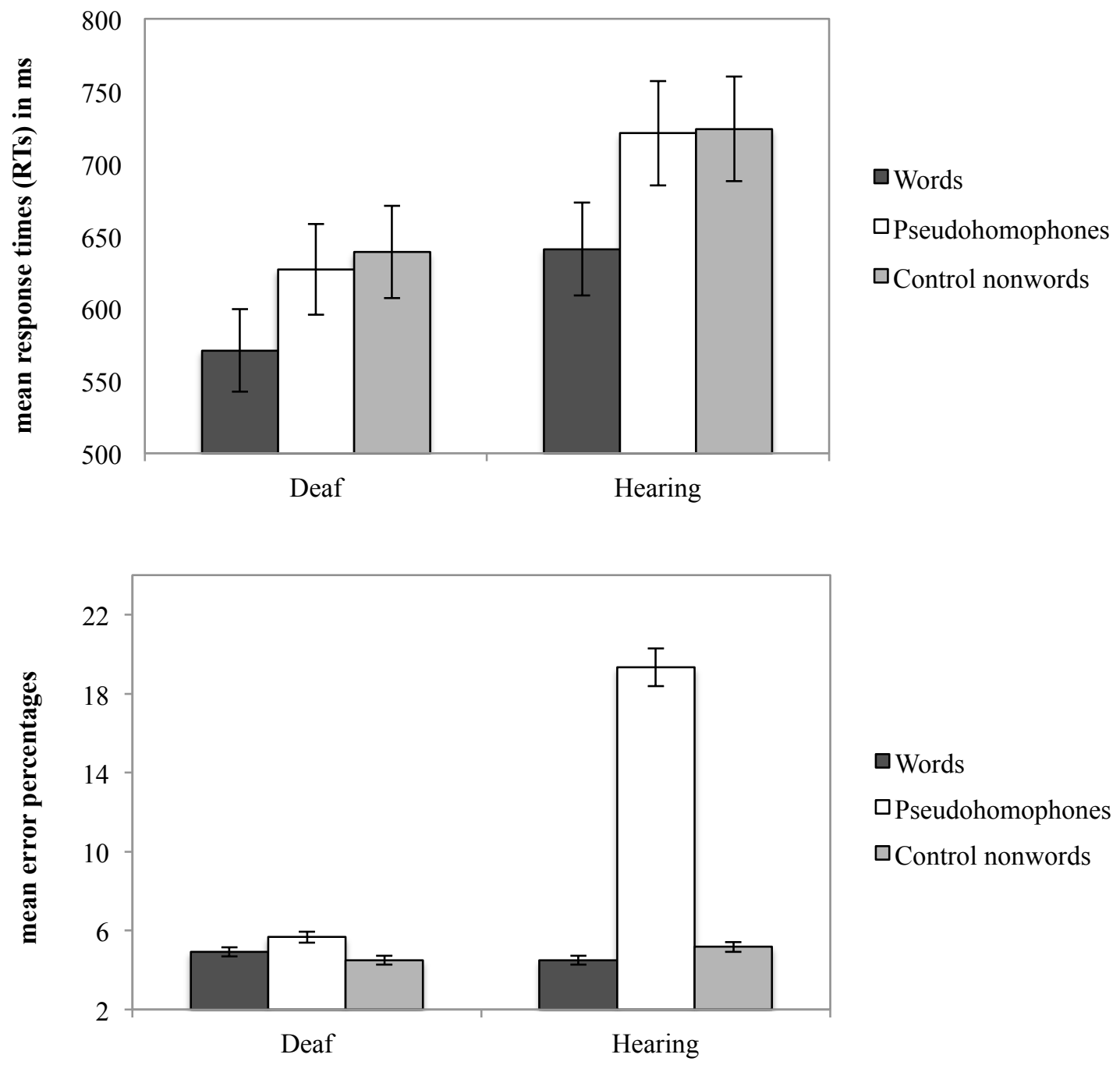

Figure 1. Mean response times (RTs) in ms and error percentages for words, pseudohomophones and control nonwords for deaf and hearing skilled readers in Experiment 1. Error bars represent $95 \%$ confidence intervals.

Word trials. Deaf readers responded significantly faster than hearing readers $(571 \mathrm{~ms}$ vs. $641 \mathrm{~ms}$; $\left.\mathrm{t}_{1}(28)=-2.93, \mathrm{p}=.007 ; \mathrm{t}_{2}(79)=-15.73, \mathrm{p}<.001\right)$. Error percentages by deaf readers and hearing readers were not significantly different $\left(4.92 \%\right.$ vs. $4.50 \%$; $\mathrm{t}_{1}(28)=0.36, \mathrm{p}>.250 ; \mathrm{t}_{2}(79)=0.45$, $\mathrm{p}>.250)$.

Nonword trials. The analysis of response latencies yielded a main effect of Group, demonstrating faster responses for deaf than hearing readers $\left(633 \mathrm{~ms}\right.$ vs. $722 \mathrm{~ms} ; \mathrm{F}_{1}(1,26)=10.89, \mathrm{p}=.003$; 
$\left.F_{2}(1,78)=424.78, p<.001\right)$. The main effect of Type of nonword was not significant

$\left(\mathrm{F}_{1}(1,26)=0.13, \mathrm{p}>.250 ; \mathrm{F}_{2}(1,78)=1.31, \mathrm{p}>.250\right)$ and the interaction between the two factors was not significant either $\left(F_{1}(1,26)=3.24, p=.083 ; F_{2}(1,78)=0.46, p>.250\right)$. The analysis of error percentages yielded a main effect of Group $\left(\mathrm{F}_{1}(1,26)=10.91, \mathrm{p}=.003 ; \mathrm{F}_{2}(1,78)=38.04, \mathrm{p}<.001\right)$ showing that deaf readers were more accurate than hearing readers (5.08\% vs. $12.25 \%)$. The main effect of Type of nonword was also significant $\left(F_{1}(1,26)=20.16, p<.001 ; F_{2}(1,78)=20.56\right.$, $\mathrm{p}<.001)$. More importantly, the interaction between the two factors was significant $\left(F_{1}(1,26)=14.95, p<.001 ; F_{2}(1,78)=26.27, p<.001\right)$, showing that hearing readers made more errors when responding to the pseudohomophomones than to the control nonwords (19.33\% vs. $\left.5.17 \% ; \mathrm{t}_{1}(14)=4.98, \mathrm{p}<.001 ; \mathrm{t}_{2}(79)=5.57, \mathrm{p}<.001\right)$, while deaf readers showed no difference between the two conditions ( $5.67 \%$ vs. $\left.4.5 \% ; \mathrm{t}_{1}(14)=0.69, \mathrm{p}>.250 ; \mathrm{t}_{2}(79)=0.65, \mathrm{p}>.250\right)$.

\section{Experiment 2: Orthographic coding}

3.1. Method

3.1.1. Participants

The participants were the same as in Experiment 1.

\subsubsection{Materials}

For the word trials, 80 Spanish words between eight and ten letters long were selected (mean $\log$ word frequency: 3.88, range: 3.45-4.48; mean number of letters: 8.73; Duchon et al., 2013). For the nonword trials, 80 Spanish base words between eight and ten letters long with a similar frequency to the first set were also selected (mean log word frequency: 3.91, range: 2.975.12; mean number of letters: 8.74). These base words were then used to create (1) a transposed- 
letter (TL) nonword in which the position of two non-adjacent consonants was swapped (e.g., mecidina from the base word medicina, 'medicine'), and (2) a replaced-letter (RL) nonword in which the two critical consonants were substituted by others with a similar physical shape as in the transposed-letter nonword (e.g., mesifina). Two lists of materials were constructed so that each base word appeared only once in each list, either as a TL nonword or as a RL nonword. Participants were randomly assigned to the two lists. In total, each participant completed 160 trials, 80 words and 80 nonwords (40 transposed-letter nonwords and 40 replaced-letter nonwords).

\subsubsection{Procedure}

The procedure was the same as in Experiment 1.

\subsubsection{Results}

Mean error percentages and response latencies for deaf and hearing readers are presented in Figure 2. Trials with incorrect responses $(8.55 \%$ and $9.47 \%$ of the trials for deaf and hearing respectively) were excluded from RT analysis. First, RTs associated with responses shorter than $200 \mathrm{~ms}$ were discarded given that they were likely to correspond to involuntary button presses ( $0.55 \%$ and $1.52 \%$ of the data of deaf and hearing group, respectively). Next, RTs above or below 2.5 standard deviations from the mean for each condition per participant were also excluded from the analysis of the response latencies $(2.14 \%$ of the data of the deaf group and $1.33 \%$ of the data of the hearing group). For nonwords trials, participants- and items-based ANOVAs were conducted on error percentages and response latencies based on a 2 (Group: hearing, deaf) x 2 (Type of nonword: transposed-letter, replaced-letter) design. 

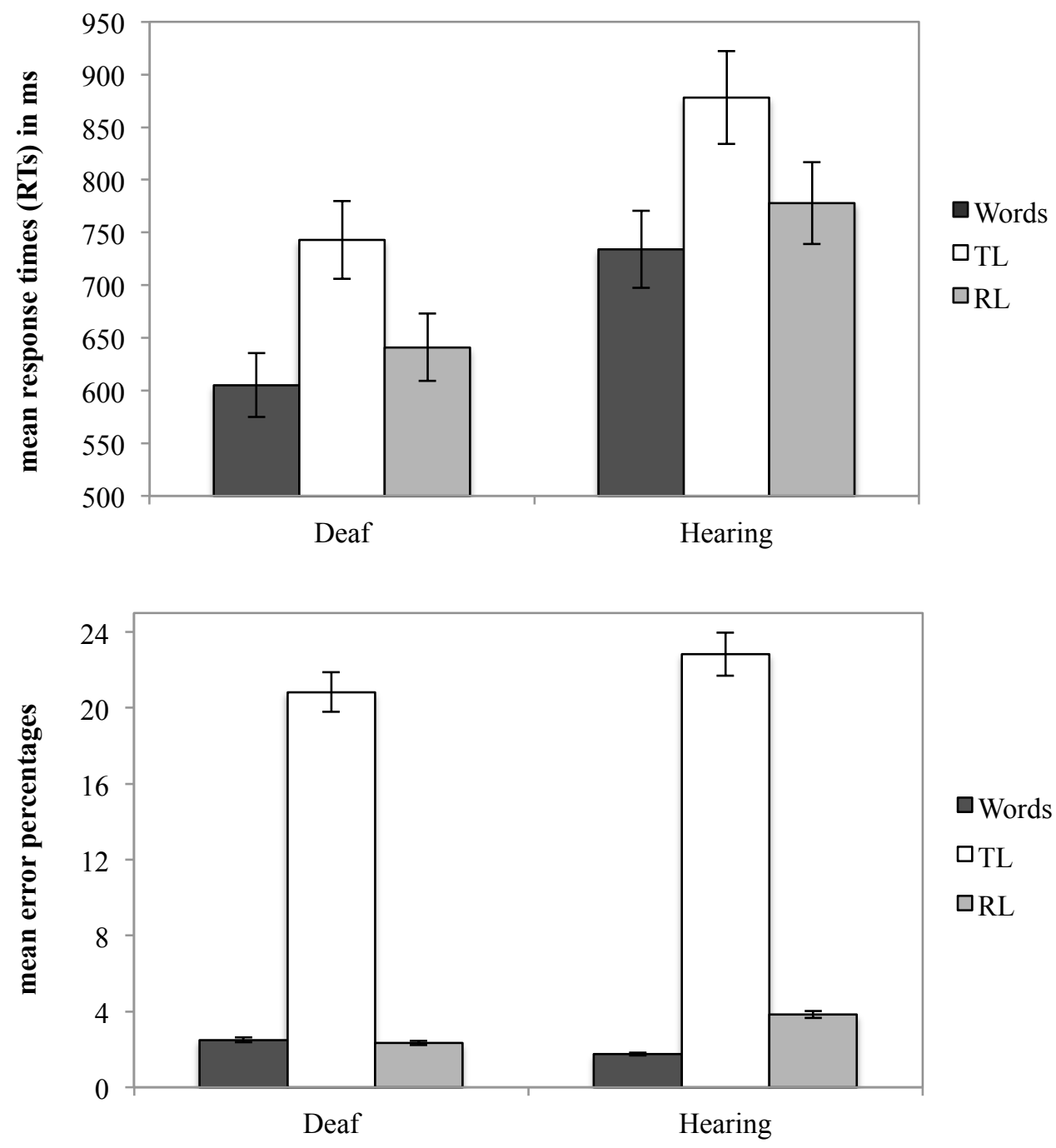

Figure 2. Mean response times (RTs) in ms and error percentages for words, transposed-letter and replaced-letter nonwords for deaf and hearing skilled readers in Experiment 2. Error bars represent $95 \%$ confidence intervals.

Word trials. Deaf readers responded faster than hearing readers $\left(605 \mathrm{~ms}\right.$ vs. $734 \mathrm{~ms} ; \mathrm{t}_{1}(28)=-3.50$, $\left.\mathrm{p}=.002 ; \mathrm{t}_{2}(79)=-28.39, \mathrm{p}<.001\right)$. Error percentages were not significantly different for deaf readers and hearing readers $\left(2.50 \%\right.$ vs. $\left.1.75 \% ; \mathrm{t}_{1}(28)=0.87, \mathrm{p}>.250 ; \mathrm{t}_{2}(79)=1.07, \mathrm{p}>.250\right)$.

Nonword trials. The analysis of response latencies yielded a main effect of Group, indicating that deaf skilled readers responded faster than hearing readers $\left(692 \mathrm{~ms}\right.$ vs. $828 \mathrm{~ms} ; \mathrm{F}_{1}(1,26)=16.32$, 
$\left.\mathrm{p}<.001 ; \mathrm{F}_{2}(1,77)=384.78, \mathrm{p}<.001\right)$. A main effect of Type of nonword was also found $\left(\mathrm{F}_{1}(1,26)=102.44, \mathrm{p}<.001 ; \mathrm{F}_{2}(1,77)=159.06, \mathrm{p}<.001\right)$, showing faster responses for replaced-letter nonwords than transposed-letter nonwords $(709 \mathrm{~ms}$ vs. $810 \mathrm{~ms})$. The interaction between the two factors was not significant $\left(F_{1}(1,26)=0.02, p>.250 ; F_{2}(1,77)=0.40, p>.250\right)$. The analysis of error percentages yielded a main effect of Type of nonword $\left(\mathrm{F}_{1}(1,26)=62.16, \mathrm{p}<.001 ; \mathrm{F}_{2}(1,78)=78.04\right.$, $\mathrm{p}<.001)$, indicating that participants made more errors in the transposed-letter condition than in the replaced-letter condition ( $21.83 \%$ vs. $3.08 \%)$. The main effect of Group was not significant $\left(\mathrm{F}_{1}(1,26)=0.43, \mathrm{p}>.250 ; \mathrm{F}_{2}(1,78)=1.91, \mathrm{p}=.171\right)$. The interaction between the two factors was not significant either $\left(\mathrm{F}_{1}(1,26)=0.03, \mathrm{p}>.250 ; \mathrm{F}_{2}(1,78)=0.13, \mathrm{p}>.250\right)$.

\section{General Discussion}

Taken together, these results showed a critical difference between deaf and hearing skilled readers in the influence of phonological coding during visual word processing. In contrast to hearing readers, deaf skilled readers were not sensitive to pseudohomophones (Experiment 1). However, this was not the case for orthographic coding, since similarly to hearing readers, deaf individuals were slower to reject transposed-letter nonwords compared to control nonwords (Experiment 2). As such, there were negligible differences between the groups in their access to orthographic information. Also, surprisingly, deaf readers recognized words and non-words faster than hearing readers and more accurately.

Firstly, the results of Experiment 1 replicate the pseudohomophone effect in hearing individuals, who showed a higher percentage of errors when rejecting pseudohomophones compared to control nonwords. Thus, hearing readers experienced greater difficulty rejecting 
nonwords that are pronounced like real words (Briesemeister et al., 2009). This suggests some interference of phonological information during lexical access, which provides evidence for the role of phonological information during visual-word identification. While the pseudohomophone effects reported in this study were only found in the errors rates, and not in the reaction time analysis, this is not such an uncommon finding. It should be considered that the stimuli used this experiment were relatively short (4-6 letters) and based on high frequency words, and some preceding studies have also failed at finding significant pseudohomophone effects for highfrequency items (e.g., Braun et al., 2015), and others have exclusively found the effects in the error data (e.g., Briesemeister et al., 2009). Importantly, for deaf skilled readers error percentages were similar for pseudohomophones and control nonwords, suggesting that they did not activate phonological codes. Since our sample of deaf readers showed proficient reading scores but no evidence of phonological encoding, these results cast doubt on the hypothesis that deaf individuals need to access phonology in reading tasks to be competent readers (Perfetti \& Sandak, 2000).

Interestingly, this apparent lack of phonological encoding in deaf readers is consistent with the results obtained by Bélanger et al. (2012) in their study with deaf readers of French, a language with an opaque orthography, in which even hearing readers are expected to more strongly rely on orthographic encoding. That is, for languages with opaque orthographies, phonological mediation may not be a prerequisite for semantic access (e.g., Taft \& van Graan, 1998). The present study examined reading in a language with a transparent orthography, for which the Orthographic Depth Hypothesis (Frost \& Katz, 1992) predicts that hearing readers rely on phonological coding during reading. The present data demonstrate that, in contrast to hearing readers, deaf Spanish skilled readers do not appear to make use of phonological representations 
during visual word recognition. Further investigation is needed to describe the role of phonology in deaf people with less reading skills. Importantly, the present data support the idea that deaf people are able to read words in a transparent language without requiring an activation of phonological coding, in contrast to hearing peers. The puzzle, then, is to explain how deaf readers achieve competence in reading in a language with a transparent orthography in the absence of phonological encoding.

Experiment 2 showed that both deaf skilled readers and hearing readers were slower and less accurate rejecting transposed-letter nonwords compared to replaced-letter nonwords. This replicates the classic transposed-letter effect in hearing readers in a lexical decision task, where transposed-letter nonwords have higher latency response and error rate than replaced-letter nonwords (Chambers, 1979; O'Connor \& Forster, 1981), and extends the findings to deaf skilled readers. Previous studies have suggested that the transposed-letter effect reflects orthographic processing (Perea \& Carreiras, 2006), and the current results therefore demonstrate that deaf skilled readers are as sensitive as hearing controls to orthographic processes. Taken together with the outcome from Experiment 1, these results suggest that deaf skilled readers more strongly rely on orthographic processing than phonological processing during reading and that there may be a direct association between orthographic representations and word meaning (see Harris \& Moreno, 2004, for a similar argument).

A somewhat surprising finding in the present study was that deaf readers were significantly faster than hearing readers across conditions in both experiments, consistent with previous studies (Brown \& Brewer, 1996; Hanson \& Fowler, 1987; Morford, Occhino-Kehoe, Piñar, Wilkinson, \& Kroll, 2015). Several studies have found faster responses for deaf than hearing participants on other visual tasks, such as perceptual thresholds tasks (Nava, Bottari, 
Zampini, \& Pavani, 2008) or simple detection and lateralization tasks (Colmenero, Catena, Fuentes, \& Ramos, 2004; Lore \& Song, 1991; Reynolds, 1993). In a review by Pavani and Bottari (2012) on the last years of research on visual abilities in deaf people, they concluded that deaf people do not have better visual skills compared to hearing, but they are faster in tasks with visual stimuli. Perhaps, the level of motivation and attitude could possibly explain the divergence of times between groups: the deaf group may have been especially eager to participate in the experiment because they knew that the research could be important for the deaf community. Another possible explanation is that the absence of phonological encoding makes word recognition faster for deaf readers than for hearing readers. Lexical access (or lexical decision) may occur more rapidly for deaf readers than for hearing readers as a consequence of the diminished dispersion of the activation among phonological competitors for deaf people than for the hearing. Other studies are consistent with this interpretation (Morford et al., 2015). Clearly, further research is required with this population (yet with others types of lexical and sub-lexical tasks) to verify whether the reaction times of both groups are different or similar, depending on the type of task and processing. Still, it remains to be seen what kind of strategies and alternative mechanisms use deaf skilled readers to efficiently read in the absence of phonological activation.

To conclude, the present study revealed both differences and similarities between deaf and hearing skilled readers. In particular, our findings suggest that the activation of phonological coding is not necessary for deaf individuals when reading words in a transparent language. However, similar to hearing readers, deaf skilled readers were sensitive to orthographic manipulations. Although automatic phonological encoding may usually be the default mechanism for reading in transparent orthographies, it is not required for successful visual word recognition. The special case of deaf skilled readers demonstrates that reading may rely solely on 
orthographic encoding, without the need for phonological encoding. Hence, efficient phonological processing is not a prerequisite step for word identification in languages with transparent orthographies. 


\section{Author Contributions}

N. Fariña, J. A. Duñabeitia and M. Carreiras developed the study concept. All authors contributed to the study design. N. Fariña performed testing and data collection under the supervision of. J. A. Duñabeitia and M. Carreiras. All authors drafted the manuscript, and provided critical revisions. All authors approved the final version of the manuscript for submission.

\section{Acknowledgments}

This project would have not been possible without the help of the CNSE (State Confederation of Deaf People), many deaf associations of Spain and two universities (Pompeu Fabra University in Barcelona and University of La Laguna in Tenerife), which provided useful spaces in which to run the experiments.

Various colleagues have provided invaluable support: Sign Language Group of the BCBL, Moisés Betancort and Juan Andrés Hernández.

Finally, thanks to all deaf people and the hearing controls that have participated in the experiments.

This study was partially supported by grants from the Spanish Government (SEV-20150490, PSI2015-67353-R and PSI2015-65689-P), by a grant from the European Research Council (ERC-2011-ADG-295362), and by a 2016 BBVA Foundation Grant for Researchers and Cultural Creators awarded to JAD. 


\section{References}

Aparicio, M., Gounot, D., Demont, E., \& Metz-Lutz, M. N. (2007). Phonological processing in relation to reading: an fMRI study in deaf readers. Neuroimage, 35(3), 1303-1316.

Bavelier, D., Dye, M. W., \& Hauser, P. C. (2006). Do deaf individuals see better? Trends in cognitive sciences, 10(11), 512-518.

Bélanger, N. N., Baum, S. R., \& Mayberry, R. I. (2012). Reading difficulties in adult deaf readers of French: Phonological codes, not guilty! Scientific Studies of Reading, 16(3), $263-285$.

Bélanger, N. N., Mayberry, R. I., \& Rayner, K. (2013). Orthographic and phonological preview benefits: Parafoveal processing in skilled and less-skilled deaf readers. The Quarterly journal of experimental psychology, 66(11), 2237-2252.

Braun, M., Hutzler, F., Münte, T. F., Rotte, M., Dambacher, M., Richlan, F., \& Jacobs, A. M. (2015). The neural bases of the pseudohomophone effect: Phonological constraints on lexico-semantic access in reading. Neuroscience, 295, 151-163.

Briesemeister, B. B., Hofmann, M. J., Tamm, S., Kuchinke, L., Braun, M., \& Jacobs, A. M. (2009). The pseudohomophone effect: Evidence for an orthography-phonologyconflict. Neuroscience letters, 455(2), 124-128.

Brown, P. M., \& Brewer, L. C. (1996). Cognitive processes of deaf and hearing skilled and less skilled readers. Journal of Deaf Studies and Deaf Education, 1(4), 263-270.

Campbell, R., \& Wright, H. (1988). Deafness, spelling and rhyme: How spelling supports written word and picture rhyming skills in deaf subjects. The Quarterly Journal of Experimental Psychology, 40(4), 771-788. 
Carreiras, M., Perea, M., Vergara, M., \& Pollatsek, A. (2009). The time course of orthography and phonology: ERP correlates of masked priming effects in Spanish. Psychophysiology, 46(5), 1113-1122.

Carreiras, M., Seghier, M. L., Baquero, S., Estévez, A., Lozano, A., Devlin, J. T., \& Price, C. J. (2009). An anatomical signature for literacy. Nature, 461(7266), 983-986.

Catts, H. W., Hogan, T. P., \& Adolf, S. M. (2005). Developmental changes in reading and reading disabilities. In H. W. Catts (Ed.), The connection between language and reading disabilities (pp. 23-36). Mahwah, NJ: LEA.

Chambers, S. M. (1979). Letter and order information in lexical access. Journal of Verbal Learning and Verbal Behavior, 18(2), 225-241.

Colin, S., Magnan, A., Ecalle, J., \& Leybaert, J. (2007). Relation between deaf children's phonological skills in kindergarten and word recognition performance in first grade. Journal of Child Psychology and Psychiatry, 48(2), 139-146.

Colmenero, J. M., Catena, A., Fuentes, L. J., \& Ramos, M. M. (2004). Mechanisms of visuospatial orienting in deafness. European Journal of Cognitive Psychology, 16(6), 791-805.

Coltheart, M., Rastle, K., Perry, C., Langdon, R., \& Ziegler, J. (2001). DRC: a dual route cascaded model of visual word recognition and reading aloud. Psychological review, 108(1), 204.

Conrad, R. (1979). The deaf schoolchild: Language and cognitive function. HarperCollins Publishers. 
De Bruin, A., Carreiras, M., \& Duñabeitia, J.A. (2017). The BEST dataset of language proficiency. Frontiers in Psychology, 8, 522.

De la Cruz, M.V. (1999). ECL-2. Evaluación de la comprensión lectora. Madrid: TEA.

Duchon, A., Perea, M., Sebastián-Gallés, N., Martí, A., \& Carreiras, M. (2013). EsPal: Onestop shopping for Spanish word properties. Behavior research methods, 45(4), 12461258.

Dyer, A., MacSweeney, M., Szczerbinski, M., Green, L., \& Campbell, R. (2003). Predictors of reading delay in deaf adolescents: The relative contributions of rapid automatized naming speed and phonological awareness and decoding. Journal of Deaf Studies and Deaf Education, 8(3), 215-229.

Ehri, L. C. (1986). Sources of difficulty in learning to spell and read. Advances in Developmental \& Behavioral Pediatrics.

Ferrand, L., \& Grainger, J. (1994). Effects of orthography are independent of phonology in masked form priming. The Quarterly Journal of Experimental Psychology, 47(2), 365382.

Frith, U. (1985). Beneath the surface of developmental dyslexia. Surface dyslexia, 32.

Frost, R. (1998). Toward a strong phonological theory of visual word recognition: true issues and false trails. Psychological bulletin, 123(1), 71.

Frost, R., \& Katz, L. (1989). Orthographic depth and the interaction of visual and auditory processing in word recognition. Memory \& Cognition, 17(3), 302-310. 
Frost, R., \& Katz, L. (1992). The reading process is different for different orthographies: The orthographic depth hypothesis. Orthography, phonology, morphology and meaning, 94, 67.

Frost, R., Repp, B. H., \& Katz, L. (1988). Can speech perception be influenced by simultaneous presentation of print? Journal of Memory and Language, 27(6), 741-755.

Hanson, V. L., \& Fowler, C. A. (1987). Phonological coding in word reading: Evidence from hearing and deaf readers. Memory \& Cognition, 15(3), 199-207.

Harm, M. W., \& Seidenberg, M. S. (2004). Computing the meanings of words in reading: cooperative division of labor between visual and phonological processes. Psychological review, $111(3), 662$.

Harris, M., \& Moreno, C. (2004). Deaf children's use of phonological coding: Evidence from reading, spelling, and working memory. Journal of Deaf Studies and Deaf Education, $9(3), 253-268$.

Izura, C., Cuetos, F., \& Brysbaert, M. (2014). Lextale-Esp: A test to rapidly and efficiently assess the Spanish vocabulary size. Psicológica, 35(1), 49-66.

Izzo, A. (2002). Phonemic awareness and reading ability: An investigation with young readers who are deaf. American Annals of the Deaf, 147(4), 18-28.

Kelly, L., \& Barac-Cikoja, D. (2007). The comprehension of skilled deaf readers: The roles of word recognition and other potentially critical aspects of competence. In K. Cain \& J. Oakhill (Eds.), Children's comprehension problems in oral and written language: A cognitive perspective (pp. 244-279). New York: Guilford Press. 
Lemhöfer, K., \& Broersma, M. (2012). Introducing LexTALE: A quick and valid lexical test for advanced learners of English. Behavior Research Methods, 44(2), 325-343.

Lore, W. H., \& Song, S. (1991). Central and peripheral visual processing in hearing and nonhearing individuals. Bulletin of the Psychonomic Society, 29(5), 437-440.

Mayberry, R. I., Del Giudice, A. A., \& Lieberman, A. M. (2011). Reading achievement in relation to phonological coding and awareness in deaf readers: A meta-analysis. Journal of Deaf Studies and Deaf Education, 16(2), 164-188.

Mayer, C. (2007). What really matters in the early literacy development of deaf children. Journal of Deaf Studies and Deaf Education.

Morford, J. P., Occhino-Kehoe, C., Piñar, P., Wilkinson, E., \& Kroll, J. F. (2015). The time course of cross language activation in deaf ASL English bilinguals. Bilingualism: Language and Cognition, 1-14.

Nava, E., Bottari, D., Zampini, M., \& Pavani, F. (2008). Visual temporal order judgment in profoundly deaf individuals. Experimental brain research, 190(2), 179-188.

Nielsen, D. C., \& Luetke-Stahlman, B. (2002). Phonological awareness: One key to the reading proficiency of deaf children. American Annals of the Deaf, 147(3), 11-19.

O’Connor, R. E., \& Forster, K. I. (1981). Criterion bias and search sequence bias in word recognition. Memory \& Cognition, $9(1), 78-92$.

Pavani, F., \& Bottari, D. (2011). Visual abilities in individuals with profound deafness: A critical review. In M. M. Murray \& M. T. Wallace (Eds.), The neural bases of multisensory processes (pp. 423-448). Boca Raton: CRC Press. 
Perea, M., \& Carreiras, M. (2006). Do transposed-letter similarity effects occur at a prelexical phonological level?. The Quarterly journal of experimental psychology, 59(9), 16001613.

Perea, M., \& Lupker, S. J. (2004). Can CANISO activate CASINO? Transposed-letter similarity effects with nonadjacent letter positions. Journal of memory and language, $51(2), 231-246$.

Perfetti, C. A., \& Sandak, R. (2000). Reading optimally builds on spoken language: Implications for deaf readers. Journal of Deaf Studies and Deaf Education, 5(1), 32-50.

Pollatsek, A., Perea, M., \& Carreiras, M. (2005). Doesconal prime canal more thancinal? Masked phonological priming effects in Spanish with the lexical decision task. Memory \& cognition, 33(3), 557-565.

Raven, J., Raven, J. C. \& Court, J.H. (1998). Manual for Raven's progressive matrices and vocabulary scales.

Reynolds, H. N. (1993). Effects of foveal stimulation on peripheral visual processing and laterality in deaf and hearing subjects. The American journal of psychology, 523-540.

Scarborough, H. S., Catts, H. W., \& Kamhi, A. G. (2005). Developmental relationships between language and reading: Reconciling a beautiful hypothesis with some ugly facts. The connections between language and reading disabilities, 3-24.

Share, D. L. (1995). Phonological recoding and self-teaching: Sine qua non of reading acquisition. Cognition, 55(2), 151-218.

Taft, M., \& Van Graan, F. (1998). Lack of phonological mediation in a semantic categorization task. Journal of memory and language, 38(2), 203-224. 
Transler, C., Leybaert, J., \& Gombert, J. (1999). Do deaf children use phonological syllables as reading units?. Journal of deaf studies and deaf education, 4(2), 124-143.

Transler, C., \& Reitsma, P. (2005). Phonological coding in reading of deaf children: Pseudohomophone effects in lexical decision. British Journal of Developmental Psychology, 23(4), 525-542.

Traxler, C. B. (2000). The Stanford Achievement Test: National norming and performance standards for deaf and hard-of-hearing students. Journal of deaf studies and deaf education, 5(4), 337-348.

Van Orden, G. C., Johnston, J. C., \& Hale, B. L. (1988). Word identification in reading proceeds from spelling to sound to meaning. Journal of Experimental Psychology: Learning, Memory, and Cognition, 14(3), 371.

Ziegler, J. C., \& Ferrand, L. (1998). Orthography shapes the perception of speech: The consistency effect in auditory word recognition. Psychonomic Bulletin \& Review, 5(4), 683-689.

Ziegler, J. C., Jacobs, A. M., \& Klüppel, D. (2001). Pseudohomophone effects in lexical decision: still a challenge for current word recognition models. Journal of Experimental Psychology: Human Perception and Performance, 27(3), 547. 